\title{
Los bandidos y la identidad california en la segunda mitad del XIX: Tiburcio Vasquez
}

\author{
por \\ Covadonga Lamar Prieto \\ University of California Riverside \\ covadonga.lamar-prieto@ucr.edu
}

El bandido Tiburcio Vasquez desarrolla su carrera en un momento de dificultad política y social para los californios, que desde 1848 pasan a formar parte de EEUU. Se examinan la entrevista bilingüe que Vasquez concede en la víspera de su ajusticiamiento, así como fuentes contemporáneas en inglés y en español sobre él. Desde el marco teórico de la liminalidad, se muestran las herramientas por las que se folcloriza el pasado californio, además de la conceptualización de Vasquez como bandido y quiénes originan esos juicios. Se concluye que los bandidos californios, y especialmente Vasquez, representan la disolución parcial de la identidad california, empujada por el marco social y político de EEUU.

Palabras clave: bandido; California; siglo XIX; liminalidad; bilingüe; californio.

«Están alucinados y sueñan con Californias». Valle Inclán, La Corte de los milagros.

\section{OBJETIVO DEL TRABAJO}

Con la incorporación de la Alta California a los Estados Unidos en 1848, la situación de los pobladores hispanos del área va a cambiar radicalmente. De constituirse en el centro de la estructura social, van a verse enfrentados a una sociedad que se articulará en torno a presupuestos anglocéntricos. Tras la Constitución de 1880 , y muy a pesar de la de $1850^{1}$, la mayoría de los

\footnotetext{
1 Lamar Prieto, 2013: 387-409.
} 
californios quedan relegados a una posición social mucho menos privilegiada que aquella a la que estaban acostumbrados. La progresiva marginalización sociolingüística y política del grupo contribuyó a que se radicalizaran las posturas, tanto de los californios como de un buen número de los pobladores anglosajones, además de a que se criminalizase o justificase su radicalización, según el caso.

A pesar de una legislación de intenciones benevolentes -que al parecer nunca se ejecutó de forma apropiada-, los pobladores hispanos van a sentirse perjudicados dentro del nuevo marco nacional estadounidense. Entre el modelo social que traían consigo los estadounidenses y el que estaba en uso en la California anterior a la anexión se produce un escarpado salto: de una sociedad primordialmente agraria a aquella otra que se va a transformar en símbolo de la modernidad, tal y como ha sido definida por Giddens ${ }^{2}$.

En el presente trabajo, leeremos la situación de los californios partiendo del análisis de uno de sus bandidos más célebres: Tiburcio Vasquez ${ }^{3}$. Pero no lo analizaremos tan solo basándonos en lo que otros dicen de él, sino por medio de sus propias palabras. Mostraremos cómo el bandido se transforma en epítome del período de transición -lingüística, social, política- de los californios desde ser españoles y luego mexicanos, a transformarse en ciudadanos de los Estados Unidos.

Examinaremos la entrevista que le hace el periódico Los Angeles Daily Star el 16 de mayo de 1874 en la víspera de su ajusticiamiento, y que editará en un pequeño volumen Truman ${ }^{4}$. En esa entrevista, Vasquez explica que se lanzó a los caminos a causa de la situación política y social de los californios como consecuencia de la afluencia masiva de anglosajones a California. La intención de Vasquez de proclamarse en héroe de los californios contrasta con la visión que, de él, van a dar los periódicos de áreas en las que se empleaba mayoritariamente el inglés. Al pretender erigirse en símbolo de la resistencia california al nuevo orden estadounidense, Vasquez devela una conceptualización interna acerca de la diferencia racial, o cultural, de la California de la época. Es en esa franja entre la identidad compartida california y el nuevo orden político donde la figura de Vasquez se erige en símbolo del cambio social que va a experimentar California tras la incorporación a los Estados Unidos.

2 Giddens, 1990.

${ }^{3}$ La grafía del apellido varía en las fuentes: «Vásquez», «Vázquez», «Vasquez»y «Vazquez». La más común, y la que usaremos, es «Vasquez». Nótese que es una traducción al inglés, ya que carece de tilde.

4 Truman, 1874. Se puede encontrar también en Los Angeles Daily Herald, (Los Angeles [Calif.]), 07 Jan. 1875: 1b, Chronicling America: Historic American Newspapers, Lib. of Congress, <http://chroniclingamerica.loc.gov/lccn/sn84038806/1875-01-07/ed-1/seq-3/>. 
Aunque determinados aspectos de esta perspectiva han sido ya explorados por autores previos ${ }^{5}$, en este artículo situaremos en paralelo el análisis histórico con el sociocultural. De esta forma, la figura del bandido quedará puesta de relevancia desde una perspectiva multidisciplinar que incluye métodos de la sociolingüística histórica y del análisis literario. De la sociolingüística tomaremos el análisis del discurso bilingüe en las comunidades en las que se produce contacto de lenguas, en la línea en la que lo han examinado Ana Celia Zentella ${ }^{6}$ y Claudia Parodi ${ }^{7}$ para el caso del español en los Estados Unidos. Emplearemos el análisis literario como subtexto para examinar la forma en que se construye el personaje del bandido, y cuáles son los elementos que lo vinculan a la tradición ibérica aurisecular del honor y la honra. Asimismo, examinaremos la forma en que los elementos de la poética clásica aristotélica configuran el germen sobre el que se edifica la historia del bandido.

En primer lugar, este trabajo se acerca brevemente a los avatares de la historia política de California, así como a la situación lingüística de los pobladores hispanos del área durante el siglo XIX. A continuación, se analiza la forma de intervención política que suponían estos bandidos dentro del contexto más amplio de la anexión de California a los Estados Unidos. Por último, y a través del texto de la entrevista de Tiburcio Vázquez, podremos ver cómo los bandidos ejemplifican un deslizamiento conceptual, desde la posición central a la subalterna, para los californios.

En este sentido se puede entender el bandidaje como un síntoma más del choque entre el Antiguo y el Nuevo Régimen, entre las formas europeas católicas transferidas a América ${ }^{8}$ y las formas protestantes de colonización de la tierra $^{9}$. Con origen en una sociedad rural de frontera, y de la misma manera que tantos otros bandidos, Tiburcio Vasquez y sus compañeros de oficio van ser vistos como símbolo de los oprimidos desde un bando, y como individuos que rechazan el orden lógico de la ley, desde el otro bando.

Antes de continuar, es necesaria una precisión de concepto. La Real Academia recoge «californio» como «Natural del estado de California, estado de la Unión Norteamericana». Una búsqueda más pormenorizada descubre la diferencia entre «californio» $\mathrm{y}$ «bajocalifornio», el primero al norte y el

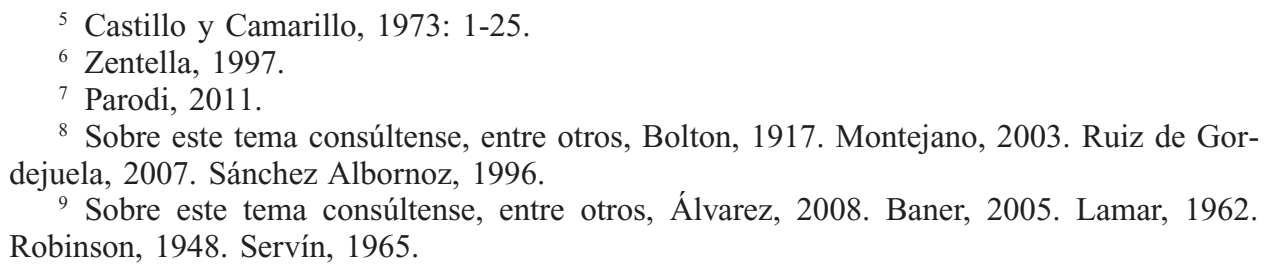

${ }^{8}$ Sobre este tema consúltense, entre otros, Bolton, 1917. Montejano, 2003. Ruiz de Gordejuela, 2007. Sánchez Albornoz, 1996.

9 Sobre este tema consúltense, entre otros, Álvarez, 2008. Baner, 2005. Lamar, 1962. Robinson, 1948. Servín, 1965. 
segundo al sur de la frontera mexicano-estadounidense. En el tiempo de Tiburcio Vasquez, el «bajocalifornio» se definía por oposición a «californio» o «altocalifornio», con ligera preferencia hacia el primero. El gentilicio en uso contemporáneamente, al menos de acuerdo con el CREA, es «californiano». Con el objeto de vincular la noción de californidad, si se permite el neologismo, con el hecho histórico de la presencia anterior al siglo XX de hispanos en el territorio, usaré «californio» como diferente de «californiano». Mientras que el primero denotará al hablante de español en la California del XIX -la que fue española, mexicana y estadounidense a lo largo del mismo siglo-, la Alta California transformada en estadounidenses, el segundo se empleará como referente del uso contemporáneo del gentilicio.

\section{FUENTES}

Las fuentes primarias del presente trabajo se organizan en dos ejes. Por un lado, emplearemos artículos aparecidos en la prensa californiana durante aproximadamente el último tercio del siglo XIX, entre 1874 y 1900. La primera de las fechas se corresponde con la captura y ajusticiamiento del bandido, mientras que la segunda obedece al momento en que comienza a solidificarse el interés folclorizante en el pasado californio. Emplearemos también dos volúmenes que se editan como separatas de los periódicos a los que pertenecieron, y que constituyen la base de los estudios posteriores sobre la figura del bandido. Veamos cada una de estas fuentes separadamente.

La fuente principal de este estudio, escasamente empleada por la crítica posterior en general, es el breve volumen bilingüe de Ben C. Truman de 1874 titulado Life, Adventures and Capture of Tiburcio Vasquez. The Great California Bandit and Murderer. El volumen que empleo es una primera edición original que se conserva en The Bancroft Library. Se trata de un folleto de cuarenta y cuatro páginas con portada y contraportada en papel amarillo. En el interior de la portada se incluye un mapa con el recorrido de la captura de Vasquez y tras este, siguen once páginas de introducción en inglés sobre la captura. Inmediatamente después, y entre las páginas catorce y veintidós, se ofrece la introducción a la entrevista con el bandido bajo el obvio título "An Interview with the Noted Bandit". Inmediatamente después figura la entrevista, que se titula "Vasquez' Case from his own Standpoint", y que se extiende hasta la página treinta. Las tres páginas que siguen se reservan para describir el lugar en que fue capturado Vasquez, circunstancia que además se aprovecha para vincularlo con otros criminales y bandidos como Murrieta. 
En la página 34 se inicia el texto en español. Hasta la página 37 se describe la "Captura de Vasquez". Se trata del mismo relato que figura en la introducción a la entrevista en inglés, pero en una versión mucho más reducida. Lo mismo sucede con la entrevista en español (38-44). No obstante, conviene notar que no son traducciones directas, sino que la prosa es diferente en inglés y en español: es la misma historia, pero la voz narrativa es diferente. La versión en inglés, en cualquier caso, es más amplia que la versión en español.

A pesar de que este volumen es la más importante de las fuentes primarias, también emplearemos otro. Se trata de una compilación hecha por Millard F. Hoyle en 1927: Crimes and Career of Tiburcio Vasquez, The Bandit of San Benito County and Notorious Early California Outlaw. El subtítulo dice: "Compiled from newspaper accounts of the period and firsthand information from some of those who played a part in this story". De nuevo se trata de un volumen breve, de solo veintiséis páginas, con un prefacio de Hoyles y distribuido en subsecciones organizadas cronológicamente. Vasquez no tiene voz en este caso, como lo tenía en el anterior. Se trata de una narración desde la perspectiva del editor y en la que se puede apreciar inmediatamente la voluntad de presentar al bandido como un individuo temible, al tiempo que como un bandido romántico.

En la primera edición, el periódico del que Hoyle era director -el Evening Free Lancer- solicita los derechos para una publicación conjunta: además de la historia de Vasquez, se incluye The History of Joaquin Murrieta The King of California Outlaws, Whose Band Ravaged the State in the Early Fifties, de John R. Ridge. Claramente, la intención de Hoyle es establecer paralelismos entre ambos bandidos, de modo semejante a como lo hace Bancroft en su California Pastoral (1886).

Además de estas fuentes primarias, emplearemos como fuentes secundarias las noticias aparecidas en diversos periódicos de California en el último cuarto del XIX y, por último, el capítulo que Hugh Bancroft dedica a los bandidos en su California Pastoral: Banditti. En esos testimonios periodísticos buscaremos las voces de los californios y los no californios instalados en el territorio con el objeto de discernir las opiniones contemporáneas sobre Vasquez.

\section{MÉTODO}

La situación de los pobladores hispanohablantes de California fue políticamente compleja a lo largo del siglo XIX. En un primer momento, y hasta la independencia respecto a España, tanto la Alta como la Baja California fueron territorios del imperio español. Con posterioridad a 1821, y con la 
independencia de México, los californios dejaron de ser súbditos del monarca peninsular para transformarse en ciudadanos mexicanos. A pesar de formar parte de un nuevo y menos extenso eje político, los californios van a seguir constituyéndose en la liminalidad de la nación a la que desde entonces pertenecen.

Van Gennep, en su obra clásica sobre los ritos de paso, define tres etapas diferenciadas en la evolución del individuo: separación, marginación y aceptación ${ }^{10}$. No obstante, el concepto de liminalidad de Turner ${ }^{11}$ es más interesante a la hora de comprender el lugar de los bandidos californios. No se trata tanto de los ritos de paso de van Geppen, sino de los marcos dentro y fuera del tiempo en los que se conciben las sociedades que están pasando por una crisis:

The liminal is $[\ldots]$ the initial stage of a process. It therefore exhibits temporal qualities, marking a beginning as well as an end, but also duration in the unfolding of a spatio-temporal process: liminality as a generative act, a psychosocial intentionality of being ${ }^{12}$.

El bandido, como individuo liminal, se erige en centro de la communitas de Turner. Forzados a un nuevo contrato social, las diferencias sociales entre los californios nativos se tornan difusas en el período entre la primera y la segunda Constitución. En este momento de liminalidad social es cuando emerge el bandido y, como el bufón, dice lo que no debe ser dicho y hace lo que no debe ser hecho.

Liminalidad, marginalidad e inferioridad estructural son condiciones en las que a menudo se encuentran símbolos, rituales, sistemas filosóficos y obras de arte. Estas formas culturales proporcionan a las personas un conjunto de plantillas y modelos que son, a un solo nieve, reclasificaciones periódicas de la realidad y de la relación de una persona con la sociedad, la naturales y la cultura. Pero son más que clasificaciones, ya que incitan a las personas a actuar al mismo tiempo que a pensar $^{13}$.

Tiburcio Vasquez se extrae, voluntariamente, de los espacios públicos y de los espacios habitados. En lo que respecta a los primeros, y como veremos en el testimonio de Catherina Watson, se presenta al bandido como un individuo que gusta de pasar desapercibido y no darse a conocer cuando está en sociedad. Sin embargo, en un juego de apariciones y desapariciones, no

\footnotetext{
${ }^{10}$ Gennep, 2008 [1909]: 10-18.

11 Turner, 1969: 60-65.

12 Andrews y Roberts, 2012: 1.

13 Turner, 1969: 128-129.
} 
duda en hacerse manifiesto cuando lo considera oportuno. En el momento de su captura va a relatar que «After my escape, I wandered for a while in the mountains; was near enough to the parties who were searching for me to kill them if I had desired so to do» ${ }^{14}$. Además, su actividad como bandido se lleva a cabo en los caminos, al anochecer, y se refugia en espacios que están más allá de los yermos, a decir de la prensa:

West from Palmdale is the Amargosa irrigation district -rather a dismal name, for the sink of Amargosa is one of the most barren spots of the American continent. Eight or ten miles further west lies the famous Elizabeth Lake, a favorite camping ground of Tiburcio Vasquez, the Spanish bandit. Harry Morse and his men when pursuing Vasquez twice visited this little mountain lake ${ }^{15}$.

Hay un tercer punto de referencia, tras van Geppen y Turner, que querríamos traer a colación. Mientras que el primero no focaliza toda su atención en el hecho comunitario, el segundo parece dejar de lado en cierta medida la presencia del individuo en la formación identitaria de la comunidad, lo que despierta dudas sobre posibles grados de pertenencia, o sobre el significado o significados del proceso liminal en sí mismo. Nos recuerda Cohen que

[...] the arguments for nationalism must be cogent within the experience and circumstances of the individuals who interpret it as being appropriate to themselves. Nationalism becomes at once a compelling means of both locating and depicting their selves. Through their ownership of their selves, they "own" the nation, or the manner of its representation, just as they "own" culture ${ }^{16}$.

La relación que establece Cohen entre la identidad propia, la nación y la cultura es particularmente valiosa para el caso de los californios. Se produce en los californios un fenómeno que Genaro Padilla ha denominado «autobiographical narratives of dispossesion $\gg{ }^{17}$. Los californios muestran una amargura mal disimulada ante la situación social que los relega a un lugar secundario pero, al mismo tiempo, se esfuerzan en no dejar ver ese resentimiento para, con ello, poder adaptarse a la nueva sociedad que se estaba creando. Esto no implica, como veremos, que los californios carecieran de sentimientos identitarios. Antes al contrario,

14 Truman, 1874: 21.

15 The San Francisco Call, April 28 1895: 24a, (San Francisco [Calif.]), America: Historic American Newspapers, Library of Congress, <http://chroniclingamerica.loc.gov/lccn/ sn85066387/1895-04-28/ed-1/seq-24/>.

${ }^{16}$ Cohen, 1996: 809.

${ }^{17}$ Padilla, 1993, Preface: X. 
[...] to see identity as being derivable from membership of a nation or a groupbe it an ethnic, kinship, or descent group, a sect, class, gender, initiation cohort, or whatever-is implicitly to deny that individuals construe their membership and their selves in very different terms. In a sense, it renders these individuals as merely members of such collectivities, and, in so doing, posits a qualitative difference between them and us: they are satisfactorily generalizable; we are preciously individualistic ${ }^{18}$.

Se trata de un juego político al que la mayoría de los californios van a jugar con poca o nula fortuna. Es en este contexto en el que tenemos que insertar la figura del bandido californio. De hecho, este fenómeno del bandidaje está representado en todos los territorios que, de formar parte de México, pasaron a incorporarse a los Estados Unidos tras el Tratado de Guadalupe-Hidalgo de 1848. Nos encontramos con Elfego Baca en Nuevo México, Gregorio Cortés - a partir especialmente de la biografía que de él hizo Américo Castro- en Texas y Tiburcio Vázquez y el más conocido Joaquín Murrieta en California, entre otros muchos. Todos ellos existen entre la realidad y la ficción, desplazándose sigilosamente entre los resquicios de las dos identidades presentes en su sociedad como criaturas liminales en sociedades dentro de un proceso más complejo de desintegración y disolución fronteriza. Como nos recuerda Davobe, «Banditry suggests a specific relationship to territoriality [...]. Banditry implies a principle of territorial sovereignty opposite to and competing with that of the state» ${ }^{19}$.

La noticia de la independencia se recibe en Monterrey, por ejemplo, con varios meses de retraso. El proceso es el que sigue: los edictos y proclamas del gobierno central llegarán, impresos, a la capital, que primero fue Monterrey y que, a partir del 23 de mayo de 1835 será Los Ángeles ${ }^{20}$. Los documentos que lleguen al despacho del Gobernador incluirán un espacio en blanco para escribir a mano el día y el mes en el que toman efecto en el área geográfica correspondiente. Baste como ejemplo la Proclama del 14 de febrero como día festivo en honor de Vicente Guerrero, conservada entre los documentos originales que atesora The Bancroft Library de la Universidad de California Berkeley. En ella se lee, al final del documento que he transcrito para mi corpus sobre el español histórico de California:

Por tanto, mando se imprima, publique, circule y se le dé el debido cumplimiento. Palacio del Gobierno federal en México á 12 de Febrero de 1834.- Valentin Gomez Farías.- A D. Francisco Maria Lombardo. Y lo comunico á V. para su

\footnotetext{
${ }^{18}$ Cohen, 1996: 803.

19 Davobe, 2007: 291.

${ }^{20}$ Echevarría, 1835.
} 
inteligencia y fines consiguientes. Dios y libertad. México 12 de Febrero de 1834 [rúbrica cuñada] Lombardo.

[Lo que sigue a máquina] Y para que llegue á noticia de todos y nadie alegue ignorancia, mando se publique por bando en esta Capital, se fije en los lugares públicos acostumbrados y se circule a quienes toque cuidar de su observancia. En Monterrey á [manuscrito: 28] de [manuscrito: Mayo] de $1834^{21}$.

Se proclama festivo el 12 de febrero de 1834 y se da cumplimiento a publicitarlo el 28 de mayo de 1834 en la Alta California, unas diez semanas más tarde. En este sentido, el relativo aislamiento territorial de los californios, que no debe confundirse con carencia de vínculos identitarios o patrióticos con México, va a ser crucial a la hora de construir una de las ficciones más repetidas sobre California: la supuestamente rápida y cómoda incorporación política de los californios a los Estados Unidos. Se argumenta que los californios no habían tenido tiempo siquiera de acostumbrarse a ser mexicanos cuando se transformaron en estadounidenses ${ }^{22}$. Las voces de los californios de la época, no obstante, desmontan esta teoría con rapidez. El siguiente ejemplo, extraído como el anterior de mi corpus lingüístico, pertenece a Félix Buelna, un californio del norte que se siente francamente decepcionado con la conducta de los anglófonos. Cuando reflexiona sobre su pasado, dice:

...habiamos nacido al amparo de la bandera mexicana, teníamos afecto a esa bandera y nos avergonzaba el corazon de pensar en que unos aventureros la habian pisoteado y su [proceder] aun quedaba sin ser castigado; yo no niego que Mejico durante mas de veinte años habia sido una madrastra muy cruel [...] pero cuando vimos a Mejico oprimida por una potencia extranjera, entonces callaron nuestros resentimientos y de comun acuerdo resolvimos dejar bien puesto el honor nacional ${ }^{23}$.

No conviene tampoco olvidar, a la hora de pensar en la situación de California en el siglo XIX, que ningún estado en esa época poseía control exhaustivo sobre sus tierras ni sobre sus habitantes: «Ningún estado, antes del ferrocarril o el telégrafo, [...] podía saber lo que ocurría en sus rincones más lejanos o mover a sus agentes con la rapidez suficiente para que tomasen medidas», nos recuerda certeramente Hobsbawn ${ }^{24}$. Aunque es necesaria más investigación al respecto, la idea del aislamiento específico de California,

\footnotetext{
${ }^{21}$ Zamora y Figueroa, 1834: 1.

${ }^{22}$ Moreno de Alba y Perissinotto, 1998: 171-191.

${ }^{23}$ Narración de Felix Buelna, Collection of the Bancroft Library, University of California at Berkeley (MSS BANC), 64: 25. Contra Costa, 4 de julio de 1876, MSS BANC.

${ }^{24}$ Hobsbawn, 2001: 27-28.
} 
por oposición al de Nuevo México por ejemplo, es un constructo posterior condicionado por las diferentes vicisitudes políticas y sociales a las que se vio sometido el territorio.

Cuando en 1847 se firme el Tratado de Cahuenga, que se reafirmará con el de Guadalupe Hidalgo al año siguiente, los californios pasarán a ser parte de una nación diferente, una tercera nación en la que también se van a constituir en la frontera más distante dentro de la masa continental. En un esfuerzo de reescritura, o de comprensión del nuevo contexto histórico, los bandidos se configuran en una más de las resonancias de ese pasado californio, en el momento en que la californidad comenzaba a ser definida en términos anglosajones. No podemos olvidar que, a diferencia de los demás territorios mexicanos incorporados tras Guadalupe-Hidalgo, California se transformará en estado de la Unión muy rápidamente.

La primera Constitución de California como estado de la Unión se aprobará en 1849 y se ratificará en la primera semana de 1850. En ella, haciéndose eco de las disposiciones del Tratado de Guadalupe-Hidalgo (1848), se permitirá a los mexicanos que permanezcan en la Alta California -ya denominada solo «California» desde este momento- que sin perjuicio puedan mantener su nacionalidad o adoptar la estadounidense (Art. VIII). También se les garantizan la inviolabilidad de sus posesiones y el derecho a comunicarse con la maquinaria gubernamental en español ${ }^{25}$. Los hechos se muestran reacios a permitirnos pensar que se cumplía la ley. En el editorial del primer número de El Clamor Público, una cabecera de prensa de corta vida radicada en Los Ángeles, se lee:

Desde el año de 1849 ha existido cierta animosidad entre los Mexicanos y Americanos, tan agena (sic) de un pueblo magnánimo y libre, de manera que estos han deseado con todo su corazón que los Mexicanos todos no tuvieran mas ( $\mathrm{sic}$ ) que un solo pescuezo para cortarselo (sic). Han sufrido muchas injusticias, y principalmente en las minas, han sido abusados y maltratados impugnemente (sic). Si un Mexicano tiene por desgracia un pleito en las cortes de este Estado está seguro de perderlo. Es imposible negar esta aserción porqué (sic) conocemos a muchos infelices que así les ha sucedido apesar ( $\mathrm{sic}$ ) de los esfuerzos que han hecho para obtener sus derechos y su justicia imparcial ${ }^{26}$.

En palabras de Kanellos y Martell, el editor de El Clamor, Francisco P. Ramírez, «created a landmark in awareness that Hispanics in California were

${ }^{25}$ Lamar Prieto, 2014: 7-13.

${ }^{26}$ El Clamor Público, 1, 28 de agosto de 1855: 11. Su autor fue Francisco P. Ramírez. 
being treated as a race apart from the Euro Americans» ${ }^{27}$. El sentimiento de diferencia, de que a pesar de las leyes que buscaban la igualdad esta no se conseguía, había calado ya firmemente entre los californios en 1855. El surgimiento del primero de los bandidos californios notables, Salomón Pico, puede ser entendido como uno de los síntomas del cambio que se está produciendo en la situación de los habitantes hispanos del área. Según su propio relato, Salomón Pico se habría lanzado a los caminos a causa de los, en su opinión, injustos repartos de tierras que se habían producido tras 1848. Se trataba, argumenta, de las tierras que habían pertenecido a su familia... toda vez que su familia las había obtenido por medios igualmente dudosos de sus anteriores propietarios. Los Pico fueron una de las familias más destacadas del tiempo mexicano y de las primeras décadas del estadounidense, pero quizá por ese motivo fueron también de las más perjudicadas por el Land Act de 1851. De hecho, Salomón Pico era primo carnal de Pío Pico, el último gobernador hispano de la Alta California.

De entre los cuarenta y nueve firmantes de la Constitución de 1849, ocho son californios: José Antonio Carrillo, José María Covarrubias, Manuel Domínguez, Pablo de la Guerra, Miguel de Pedrorena, Antonio María Pico, Jacinto Rodríguez y Mariano Guadalupe Vallejo. Otros cinco pueden clasificarse como tempranos residentes del área, bien sea naturalizados mexicanos, bien casados con mujeres locales, o ambos: Abel Stearns, natural de Massachussets, se había naturalizado mexicano en la década de los 20, y más tarde se casaría con Arcadia Bandini; Hugo Reid, el apodado Scotch Paisano y muy amigo del anterior, llevaba más de dos décadas instalado en el sur de California y casado con Victoria, miembro de los Comicrabit gabrielinos, cuando se ratificó la Constitución; otro estadounidense, Thomas Larkin, habría acudido a la llamada de su hermano al principio de la década de los treinta; mientras tanto, el francés Pedro Sainsevain se había instalado en California y poco después casado con la california Paula Suñol a finales de la misma década; en la misma época se radicó el alemán John (Johannes) Sutter. Al menos trece, por lo tanto, podemos suponer que eran hablantes de español. De hecho la Constitución se redacta y se ratifica en formato bilingüe.

La segunda de las Constituciones, fechada en 1880, va a ser sustancialmente diferente a esta. Los derechos de los hispanohablantes se han reducido y la presencia de los mismos como signatories, testigos de la Constitución por así decir, es mucho más baja. Además, y tras la Land Act, los californios van a tener cada vez menos posibilidades de instalarse, o mantenerse, en su condición de terratenientes. Estos dos factores -un sistema legal en inglés y

${ }^{27}$ Kanellos y Martell, 1960: 88. 
el progresivo empobrecimiento de los californios- van a actuar conjuntamente como tierra abonada para el surgimiento de los bandidos californios en el sentido que los define Hobsbawn (2001). El choque cultural que supuso la incorporación de la Alta California a los Estados Unidos, y el casi inmediato descubrimiento de los veneros de oro, provocó un efecto llamada sobre los estadounidenses que resonó hasta la otra costa y que explica el porqué de la redistribución de las tierras y de las modificaciones legislativas. Tanto la composición poblacional como las leyes van a cambiar, de forma que los californios van a verse sobrepasados por los acontecimientos, a decir de sus testimonios. Desde el otro lado, los recién llegados buscarán comprender la sociedad que están modificando con su presencia. Además, con esos nuevos pobladores llegarán también los mitos fundacionales que van a acompañar a los californios y a folclorizarlos, a lo largo de la historia y hasta el presente: un pueblo manso, indolente, dado a la fiesta y a la hospitalidad, racialmente poco uniforme. En una de las primeras biografías de Tiburcio Vasquez se dice, a modo de introducción:

There seems to have been an ever present hostility of these later remnants of the earlier mixed Indian and Mexican stock that roamed the hills, canyons, and all the valleys of California: who owned the mighty bands of wealth producing cattle, and whose hospitality was ever generous to the stranger knocking at the gates of their haciendas ${ }^{28}$.

No obstante, y como señala Delanty, «La comunidad no es una estructura moral concluyente que determina el comportamiento, sino un recurso del que la gente podría aprovecharse». Señala acertadamente que hay un elemento que los autores anteriores dejan en el tintero: «no considera que las comunidades puedan adoptar formas violentas, cuando la comunidad se sustenta en la violencia hacia otro grupo o subgrupos dentro de este» ${ }^{29}$.

Es precisamente en este punto en el que tenemos que considerar la idea de modernidad de Giddens, en particular su «discontinuist interpretation of modern social development» ${ }^{30}$. En contra tanto de la posición de Lyotard como de las de los detractores de este, Giddens defiende que es posible erigir una epistemología coherente, incluso dentro de los rápidos cambios de la modernidad. Coincidimos con Giddeon en la no inefabilidad de la modernidad, o de la postmodernidad, y creemos que el choque entre californios y estadounidenses es un ejemplo ilustrativo de este particular. Para entender

\footnotetext{
${ }^{28}$ Hoyle, 1927: 4.

${ }^{29}$ Delanty, 2003: 63.

${ }^{30}$ Giddens, 1985: 31-34.
} 
las discontinuidades que dieron, y siguen dando, origen a la modernidad, es necesario identificar y estudiar esas discontinuidades: los elementos discontinuos, los participantes y las instituciones involucradas en el traspaso de capital social entre los californios y los estadonidenses, así como el posible solapamiento entre los unos y los otros, que muestra que la discontinuidad no es absoluta sino progresiva.

Giddens propone tres sistemas que permiten identificar las discontinuidades: el ritmo del cambio, «pace of change»; el objetivo de ese cambio, «scope of change»; y por último la índole de las instituciones en la modernidad, «nature of modern institutions $\gg{ }^{31}$. Si aplicamos este molde al caso californio, los resultados son por demás interesantes. Por lo que toca al «pace of change», Giddens destaca la importancia de la tecnología, en el caso del «scope», se centra en la interconexión, mientras que para la «nature of modern institutions», examina el sistema político de la nación-estado, el uso de fuentes de energía inanimadas $\mathrm{y}$, por último, la comodificación de los productos y de los trabajadores. Veremos cada uno de ellos separadamente, con el objeto de vislumbrar la discontinuidad entre los californios y los estadounidenses. John O'Sullivan, el creador de la noción de «Manifest Destiny», ilustra con mucha claridad los tres conceptos en su texto fundacional de 1845 cuando, al tratar sobre California, dice que:

The Anglo-Saxon foot is already on its borders. Already the advance guard of the irresistible army of Anglo-Saxon emigration has begun to pour down upon it, armed with the plough and the rifle, and marking its trail with schools and colleges, courts and representative halls, mills and meeting-houses. A population will soon be in actual occupation of California, over which it will be idle for Mexico to dream of dominion. They will necessarily become independent. All this without agency of our government, without responsibility of our people--in the natural flow of events, the spontaneous working of principles, and the adaptation of the tendencies and wants of the human race to the elemental circumstances in the midst of which they find themselves placed ${ }^{32}$.

El ritmo o «pace» del cambio va a alcanzar California a través de diferentes proyectos de ingeniería civil, primero en el norte y más adelante en el sur del joven Estado. No obstante, el motor del cambio y su objetivo o «scope» último va a ser la minería. Tras la anexión, «The next fifty years saw a tremendous change in the mining industry as the industrial revolution spread worldwide, stimulating the demand for minerals, transportation, consumer goods, new

\footnotetext{
31 Ibidem: 33

32 O'Sullivan, 1845: 6.
} 
sources of power, and capital» ${ }^{33}$. La sociedad california anterior a la anexión estaba en los albores de la industrialización y comenzaba a desarrollar un tímido comercio exterior, tal como se puede colegir de los múltiples libros de cuentas que se conservan en la Biblioteca Bancroft ${ }^{34}$. Sin embargo, y a decir de sus propios testimonios, los californios no estaban preparados para la discontinuidad que se produjo entre su horizonte de expectativas y la inmersión repentina en el protocapitalismo. De hecho, el ejemplo que ofrece Giddens como resumen de su teoría, la ciudad, se presta inmediatamente al caso californio.

Tomemos el caso de Los Ángeles como ejemplo. En el Censo de 1790, contaba con cincuenta y cinco habitantes ${ }^{35}$. El padrón de 1836 , como instancia intermedia con respecto al Censo de 1850, revela una cantidad de «gente de razón» de seiscientos tres hombres, cuatrocientas veintiún mujeres y seiscientos cincuenta y un niños, hasta un total de 1.675 habitantes, lo que supone que la ciudad se había multiplicado por treinta, un $3.045 \%$, al presentar un aumento poblacional de 1.625 personas: un $66 \%$ cada año, treinta y cinco habitantes ${ }^{36}$. En el Censo de 1850 encontramos a 3.558 individuos. Supone que la ciudad se duplica, con un $212 \%$ de aumento en catorce años, lo que equivale a un $15 \%$ al año o ciento treinta y cuatro personas más. La ciudad persistirá en su crecimiento exponencial a lo largo de las décadas siguientes: 5.728 en 1870; 11.183 en 1880; 50.395 en 1890; y 102.479 en 1900, todo ello según el US Census Bureau. A pesar de incorporar el antiguo espacio de la población california de Los Ángeles, «modern urbanism is ordered according to quite different principles from those which set off the pre-modern city from the countryside in prior periods $»{ }^{37}$.

Nos resta examinar el cambio que van a sufrir las instituciones con el cambio de gobierno. California había dejado de pertenecer a una monarquía en 1810, pero la república mexicana y la república estadounidense poseían diferentes grados de participación y de interacción ciudadana. Esto, unido

33 Limbaugh, 1998: 25.

${ }^{34}$ Cfr. Libro de cuentas: ms. 1839 Feb. 22-1841 June de José de Jesús Vallejo o Libro de cuentas del Sr. Dn. Juan R. Cooper: ms. 1827 de Juan R. Cooper, así como los múltiples libros de cuentas de las misiones, entre los que cabría destacar de esa misma época el Libro de cuentas perteneciente a la Mission de S.S. José 1834-1839, MSS BANC, 91/14c. También, Libro de cuentas del Sr. Dn. Juan R. Cooper: ms, 1827, MSS BANC, C-E 59: 25, s/1, 1827. Y además, entre otros, Vallejo, José de Jesús, Libro de cuentas: ms., 1839 Feb. 22-1841 June, MSS BANC, C-E 60, Sonoma, 22 de febrero de 1839 a junio de 1841.

35 Mason, 1998.

36 Layne, 1934: 221-223.

37 Giddens, 1990: 6. 
a la sofisticación y la especialización lingüística tanto de las instituciones como los medios de producción, con trabajos más cualificados para los hablantes de inglés o los bilingües en detrimento de los monolingües de español, produjo una auténtica discontinuidad social. No se trata tan solo de una discontinuidad metafórica entre los nacidos en la sociedad anterior a la anexión y los venidos al mundo después de esta, sino que las capacidades lingüísticas suponen una discontinuidad en la capacidad de enfrentarse a la vida política.

El bandido californio emerge en esa y de esa discontinuidad. Se trata, por lo tanto, de una manifestación cultural que transciende de la cultura a la que pertenece descubriéndose universal, una forma de comprender la identidad en disolución de la antigua California, que se estaba transformando en la nueva California.

\section{Argumento}

El 14 de octubre de 1900 el periódico The San Francisco Call dedica la página diecinueve en su edición dominical a los recuerdos de Juan Gómez y su mujer Catherina, hija de un británico apellidado Watson y de una california $^{38}$. El artículo se titula "What I remember from Joaquín Murrieta y Tiburcio Vasquez" ${ }^{39}$ y, mientras los comentarios de él no aportan especial valor a la historia, los de ella dibujan una imagen muy característica de ambos bandidos. Catherina, hija de una familia bicultural, tiene también un matrimonio bicultural, casada como está con un hispano. Desde su posición intermedia, proyecta una perspectiva interesante sobre Murrieta:

He not let any Americano alone, not to kill, except my father. It come this way. You know he kill all the men and women he meet with the light hair, but he not touch my father. Is was my father's hospitality ${ }^{40}$.

38 The San Francisco Call, October 14 1900, 19, Chronicling America: Historic American Newspapers, Library of Congress of the United States $<$ http://chroniclingamerica.loc.gov/lccn/ sn85066387/1900-10-14/ed-1/seq-19/>.

39 "Lo que recuerdo de Joaquín Murrieta y Tiburcio Vasquez". Todas las traducciones son propias.

40 The San Francisco Call, October 14 1900: 19a: «No dejó a ningún americano en paz, que no matara; salvo mi padre. Pasó así. Se sabía que él mataba todos los hombres y mujeres que se encontrara con el pelo claro, pero no tocó a mi padre. Fue la hospitalidad de mi padre». El inglés de Catherina es bastante correoso y muestra una adquisición completa pero deficiente. 
Relata cómo cuando era niña Joaquín Murrieta se habría presentado de incógnito en la casa de sus padres: «He come to my father's house and ask to sleep and eat. My father was a very hospitable man. He say: "My house is yours" and tell him to sleep in the wing of the house, with the boys» ${ }^{41}$. En el inglés de Catherina podemos observar rasgos de su bilingüismo, tales como la forma de la negación -he «not» touch my father-, la indiferenciación de la tercera persona del singular de los verbos - he «want» to pay- y la necesidad de buscar apoyo en el artículo al insertar un grupo de sustantivo y adjetivo -the light hair-, entre otros. De hecho, se puede sin esfuerzo ver cómo la sintaxis del español se trasluce en su inglés.

Continúa su relato. A pesar del susto de los muchachos con los que el bandido comparte alojamiento, atemorizados por el hecho de que duerma con sus pistolas a la cintura, el extraño se va pronto y vuelve, en esta ocasión acompañado de una caterva de forajidos. Se dirigen a la tienda de comestibles de la familia Watson, y Catherina Watson de Gómez lo describe de la siguiente forma:

He walk up to my father and order provisions - so much pounds of sugar, so much pounds of coffee, and everything. Then he say he was Joaquin Murrieta, and we, everybody, was frightened to dead. [...] When they ordered the gallons of whiskey we $[\ldots]$ think they would be drunk and kill everybody. But [...] he [Murrieta] says to my father: "Mr Watson, you are a gentleman. You are one hospitable man. I respect you. I will shake your hand, and not me nor my men shall harm you or your family. It is because of the hospitable. I will be your friend. [...] He want to pay twice too much. My father did not let him do that ${ }^{42}$.

Joaquín Murrieta se transforma de un forajido sin escrúpulos a un caballero que respeta a aquellos que le ofrecen idéntico respeto, tengan el cabello rubio o no lo tengan. A la hora de relatar la captura, muerte y decapitación de Murrieta, la historia de los Gómez no sigue la versión oficial. Preguntados por el motivo de las divergencias, dice el esposo: «Oh, the man that write,

${ }^{41}$ Ibidem 19b: «Él viene a casa de mi padre y pide dormir y comer. Mi padre era un hombre muy hospitalario. Le dice: "Mi casa es suya" and le dice que duerma en el ala de la casa, con los muchachos».

${ }^{42}$ Ibidem 19c: «Fue hacia mi padre y pidió provisiones -tantas libras de azúcar, tantas libras de café, y todo. Entonces él dijo que era Joaquín Murrieta, y nosotros, todos, estábamos asustadísimos. [...] Cuando pidió los galones de whiskey nosotros [...] pensamos que se iba a emborrachar y matar a todo el mundo. Pero [...] él [Murrieta] le dijo a mi padre: "Señor Watson, es usted un caballero. Es un hombre hospitalario. Le respeto. Le daré la mano y ni yo ni ninguno de mis hombres le haremos daño ni a usted ni a su familia”. Esto es por la hospitalidad. Seré si amigo. [...] Quería pagar el doble, pero mi padre no se lo permitió». 
he do not know. He only hear, he do not know» ${ }^{43}$. Dejando aparte su inglés quebrado, los Gómez se parapetan en la verdad del testigo, del que ve, del que participa de la escritura de la historia en la realidad, por oposición al que participa escribiendo el relato o describiendo la historia para el imaginario colectivo. En cierto modo esa situación de duda se expresa en las siguientes palabras del editorial de Los Angeles Star, periódico bilingüe editado en la ciudad del mismo nombre en la época entre Constituciones. En la sección en español se lee, el 18 de junio de 1853: «Son tan variadas y contradictorias las noticias que circulan con respecto a Joaquin que no nos atrevemos a afirmar otra cosa que aquello en lo cual estan acordes y es, en que este celebre bandido, se encuentra en las cercanias de este pueblo» ${ }^{44}$.

A continuación, los Gómez describen sus recuerdos sobre Tiburcio Vasquez. Al hablar de los dos en secuencia se produce un curioso contraste, que dibuja al segundo como menos cruel y más considerado, más dispuesto a beneficiar a los californios. Gómez toma la palabra para asegurar de Vasquez que «His family is a good family, like mine y que cuando iba a la escuela everybody know he is then a good boy ${ }^{45}$. Se trata, a los ojos de la sociedad california, de la historia de una caída en desgracia. Parece, por sus palabras posteriores, que Gómez y Vasquez habrían sido compañeros de escuela y no se habrían visto de nuevo hasta el momento en que el segundo estaba retenido esperando el patíbulo. Tras relatar Gómez el progresivo descenso a los infiernos de un Vasquez quinceañero - tras una trifulca en un bar que resulta en disparos, la muerte de un hombre y la huida del joven del que afirma que era inocente- Catherina retoma la palabra para insertar otra anécdota:

One time when we live in Monterey I send my two little boys to get milk down to the ranch of Mr Gomez's mother, at 6 o'clock in the morning. They go along together and meet a man. The man is tall and dark. He stop them and scare them. He tell them he is Vasquez, and frighten them very much. My little boy, his hair stand on end, and he say he like to run, but he is too scared. He find they speak Spanish and ask who they are, and they tell. He say he know the Watsons, and that to take back his respects. He will not hurt them, and he laugh because they are frigthened ${ }^{46}$.

${ }^{43}$ Ibidem 19d: «Oh, el hombre que lo escribió [el relato de la captura], no sabía nada. Solo había oído cosas, pero no sabía nada».

${ }_{44}^{4}$ Los Angeles Star, (Los Angeles [Calif.]), 3/6, 18 junio 1853, sección "La Estrella”: 3b.

45 The San Francisco Call, October 14 1900, 19e: «Su familia es una buena familia, como la mía» y después «Cuando iba a la escuela todo el mundo sabía que era un buen muchacho».

46 The San Francisco Call, October 14 1900: 19e-f: «Una vez cuando vivíamos en Monterrey envié a mis dos hijos pequeños a por leche al rancho de la madre del señor Gómez, a las seis de la mañana. Van juntos y se encuentran a un hombre. EL hombre es alto y moreno. 
De nuevo nos encontramos con otra perspectiva sobre el bandido. No es simplemente un forajido, sino lo que Howsbawn ha definido como «social banditry». Se trata de un individuo que, desde la ejecución de la violencia, imparte una justicia difusa que se basa en principios sociales y morales diferentes a los de aquellos que detentan el poder. Howsbawn defiende que la diferencia entre el bandido social y el individuo beligerante en conflicto está en que los primeros se transforman en forajidos y son punibles cuando se les juzga con un criterio de orden público que no es el suyo ${ }^{47}$. Se trata de un esquema social que encaja perfectamente en la sociedad california anterior a la anexión a los Estados Unidos, en la que la democracia participativa y asamblearia que llevaron consigo los estadounidenses va a chocar con la estructura que vertebraba la sociedad de los californios. De hecho, y tras la Constitución mexicana de 1836, se había reducido en el territorio mexicano la noción de «pueblo» a la de «pueblo político», esto es, los individuos con derechos sociales ${ }^{48}$. Nada tendrá que ver el lejano monarca, o el lejano presidente, con la asamblea de representantes recién instalada en Monterey. No en vano nos recuerda Pío Pico en uno de sus más célebres discursos ${ }^{49}$-que toda vez ha llegado a nosotros por intermedio de Joseph Revere ${ }^{50}$-que la sociedad que llevan consigo los estadounidenses difiere en gran medida de la de los californios. Dice, y no podemos por menos que escuchar en sus palabras un cierto eco de las de O’Sullivan que hemos visto más arriba:

Lo que estos individuos sorprendentes [aquellos que vienen de los territorios de los EEUU] puedan llevar a cabo, eso no puedo decirlo, pero sí sé que culminarán con éxito cualquier empresa que comiencen. Estos viajeros aventurados se han extendido ya a lo largo y ancho de un país que parece ser de lo más adecuado a sus preferencias. Están cultivando granjas, estableciendo viñedos, erigiendo molinos, cortando leña, construyendo talleres y haciendo un millón más de cosas que, aunque a ellos les parezcan naturales, los californios rechazamos o preferimos no hacer ${ }^{51}$.

Él los para y los asusta. Les dice que es Vasquez, y los asusta mucho. Mi hijo pequeño, con los pelos de punta, dice que quiere correr, pero que tiene demasiado miedo. Él [Vasquez] se da cuenta de que hablan español y les pregunta quiénes son, y ellos se lo dicen. Él dice que conoce a los Watsons, y que manda sus respetos. Que no les hará daño y se sonríe porque están asustados».

47 Hobsbawn, 2001: 20.

48 Guerra, 1992: 379-380.

${ }^{49}$ Lamar Prieto, 2012: 102-103.

50 Revere, 1846: 24-27.

51 Ibidem: 25. 
Es en este sentido en el que tenemos que comprender la idea de «bandido social chicano» que defienden Castillo y Camarillo y según la cual muchos de los bandidos no eran tales forajidos, sino «victims of the Anglo-American invasion of Northern Mexico [...] their actions were those of men who refused to submit to this invasion ${ }^{52}$. En la perspectiva de estos autores, el bandido social chicano, en cuyas filas se encuentra Vasquez destacadamente, sería el ídolo político de los oprimidos que roba a los opresores mientras que los más desfavorecidos le vitorean. No se trata de una distinción maniquea entre estadounidenses y californios, ya que los californios que se mantienen o alcanzan la elite social post-anexión no estarán entre los que sostuvieron a los bandidos, por ejemplo ${ }^{53}$. Boessenecker argumenta que Vasquez no es un bandido social porque roba también a hispanos ${ }^{54}$, aunque esa idea únicamente valida la de Castillo y Camarillo, y no al contrario. De hecho, esa parece la misma línea de la historia de Catherine Watson de Gómez, que menciona no obstante: «Somebody know, but everybody afraid to tell» ${ }^{55}$. Sin embargo Hoyle, nada proclive a Vasquez, comenta en su relato de la captura:

It seems certain that he keep informed of the officers by native Californians wherever he went, and it is even believed that some of the white settlers in the southern section of the state aided him in his avoidance of pursuit ${ }^{56}$.

Existen, no obstante, voces discordantes con la teoría del bandidismo social. Boessenecker, por ejemplo, considera que Salomón Pico, Joaquín Murrieta, Juan Flores y Tiburcio Vasquez, entre otros, no eran sino ladrones comunes fruto de una sociedad extremadamente violenta y carente de mujeres. A juicio del autor, es bien sabido que las sociedades sin madres, esposas y novias son mucho más violentas ${ }^{57}$. Al sesgo machista de rancio pelaje podemos aparejar un idéntico bies de paternalismo racista cuando el autor dice comprender cómo, tras ser apartados de las minas por los anglos, los mexicanos se entregaron a una vida de crimen. El ejemplo anterior se usa no con el objeto de

52 Castillo y Camarillo, 1973: 2: «Víctimas de la invasión anglo-americana del Norte de México [...] sus acciones son las que los hombres que rehúsan plegarse a la invasión».

${ }^{53}$ Ibidem, Introducción.

54 Boessenecker, 1998: 422.

55 The San Francisco Call, October 14 1900: 19f: «Todo el mundo lo sabía, pero demasiado asustados como para contarlo».

${ }^{56}$ Hoyle, 1927: 16: «Parece cierto que los californios nativos lo mantenían informado de los oficiales allá donde iba, e incluso se cree que algunos de los pobladores blancos de la parte sur del Estado le auxiliaron mientras estaba evitando ser capturado».

${ }^{57}$ Boessenecker, 1998: 427. 
escarnecer a su autor, sino para mostrar cómo los bandidos californios, y entre ellos Tiburcio Vasquez, son un constructo social fuertemente ideologizado. Lo interesante, en realidad, no es quiénes fueron, sino cómo se insertaron en el topos de los bandidos sociales, y con qué objetivo. El encasillamiento de los californios dentro de una imagen entre folclórica y degradada, unido a la progresiva pérdida de poder político -condicionada por la pérdida de tierrassignifica un antes y un después en el imaginario californio. De hecho, no será hasta el surgimiento del movimiento chicano que estos bandidos comiencen a verse desde otra perspectiva: la del oprimido que lucha por sus derechos, en vez de la del vulgar criminal que intenta salirse con la suya.

Max Parra inserta a los bandidos dentro de un mecanismo más amplio de bandidaje en el México del XIX ${ }^{58}$ que buscaba modificar la idea de «pueblo» ${ }^{59}$, al tiempo que Frazer los hace «metáfora de una masculinidad degradada y de atraso» ${ }^{60}$. La ruptura nacional entre el norte y el sur de la frontera supuso que, en las palabras también de Frazer, «las elites mexicanas usaron esta imagen para expresar sus deseos nacionalizantes y para justificar su dominio sobre las clases bajas», y añade, «mientras que los angloparlantes la usaron para explicar su propio sentido de la superioridad anglosajona» ${ }^{61}$. Esta perspectiva coincide con la de Castillo y Camarillo anteriormente mencionada.

La sociedad california anterior a la anexión va a sufrir una progresiva folclorización de su pasado, que no se limita al siglo XIX y a Ramona o The Squatter and the Don, sino que continúa avanzando en el primer tercio del siglo XX. A día de hoy, la idea que permanece en términos generales es la de una California de «fiesta and siesta», léase con su fonética en inglés. En relación a los bandidos o el bandidismo, esa imagen folclorizada continuó largamente a lo largo del siglo XX. No hay mejor muestra que Frito Bandido, leído en inglés Frito Bandito: el protagonista de los anuncios de los Fritos en los años 60. Tanto su marcado acento mexicano como su aspecto físico inciden sobre la idea que acabamos de apuntar acerca de la masculinidad degradada. Se trata de la caricatura que trascendió al imaginario colectivo acerca del chicano: un monigote que pretende ser chistoso y cuya supuesta comicidad parte del juego con la valentía de un individuo cobarde, de un bandido que se asusta de sus propios disparos. De hecho, dice: «Ay, ay, ay, ay!/ oh, I am dee Frito Bandito./ I like Frito's Corn Chips./ I love them, I do./ I want Frito's corn chips./ I'll take them, from you». Después, poco después ya, nos encontramos

\footnotetext{
58 Parra, 2007: 140.

59 Parra, 2006: 65-68.

${ }^{60}$ Frazer, 2006: 8. Ápud Parra, 2006: 66.

${ }^{61}$ Frazer, 2006: 9. Ápud Parra, 2006: 67.
} 
con el acta fundacional de la recuperación de Aztlán. Se cierra el círculo, o vuelve a comenzar. Pero antes, los bandidos del XIX.

\section{La entrevista a Tiburcio Vasquez}

El relato de la captura de Tiburcio Vasquez se publica en Los Angeles Star en 1874 editado por Ben Truman, como ya hemos mencionado. Se trata de uno de los últimos documentos bilingües publicados en el periódico, cuya tirada se inicia en la década de 1860 . En ese momento la población del condado de Los Ángeles, a decir del Censo de ese año, es mayoritariamente de origen mexicano, californio o californiano, entendiendo por este último a aquellos que habrían nacido tras la anexión en el territorio de California. De hecho, menos de un 4\% de la población procede de lugares diferentes a los mencionados ${ }^{62}$. Podemos suponer, máxime considerando que los movimientos en las patentes de ranchos fueron más lentos en el sur que en el norte de California, que se trata de un área proclive a los californios. Además, el análisis de la renta mobiliaria y del capital de los individuos censados, al compararla con otras áreas geográficas, no devuelve la idea de que se trate de un zona especialmente rica.

El texto es una separata de cuarenta y cuatro páginas que salió de la imprenta que publicaba el diario del mismo nombre, un diario angeleño también bilingüe. No obstante, la lengua principal del volumen es el inglés, ya que la sección en español no cubre el relato de la captura completa, sino únicamente una versión breve y la entrevista con el bandido. El texto dice que «aunque se hace entender bien en inglés, como es lógico prefiere hablar en español» ${ }^{63}$, pero no aclara si la entrevista fue bilingüe. Hoyle atestigua que Vasquez recibió educación en inglés y que "As a man, he [Vasquez] possessed more than an average command of the English language ${ }^{64}$. Otros periódicos de la época se hacen eco de la captura y el posterior ajusticiamiento del bandido, aunque solo en inglés. Como muestra, la noticia que sigue tomada de The San Francisco Call:

TIBURCIO VAZQUEZ- C. City. Tiburcio Vasquez, the California bandit, was hanged in the County Jail, San Jose, Santa Clara County, March 19, 1875, for the

${ }^{62}$ Federal Census. Los Angeles County, 1860.

63 Truman, 1874: 40.

${ }^{64}$ Hoyle, 1927: 5: «De adulto, tenía un conocimiento más que mediano de la lengua inglesa». 
murder of Lander Davidson at Tres Pinos, August 26, 1873, while Vasquez and his gang were robbing Snyder's store at that place. In May, 1874, Vasquez was captured near Los Angeles by Sheriff Rowlands, and on the 26th of that month was placed in the City Prison of this city en route to Salinas. Monterey County, from which place he was removed for safety to San Jose. He was convicted on the 9th of January, $1875^{65}$.

En la entrevista de Los Angeles Star, Tiburcio Vasquez da cuenta de su historia familiar, con padres ya fallecidos de origen mexicano y dos hermanos, dos hermanas y dos cuñados, todos ellos de idéntico origen. Con ello se refiere a que son altocalifornios nacidos bajo el gobierno mexicano del territorio. En la entrevista a Vasquez, publicada en el Evening Free Lance de Hollister, en California, y compilada por Hoyle nos encontramos con una serie de datos autobiográficos con los que el compilador intenta explicar la carrera delictiva del bandido. Sin embargo la versión de Truman es diferente. En cierto modo su historia resuena con la de Gómez:

My career grew out of the circumstances by which I was surrounded. As I grew up to manhood, I was in the habit of attending balls and parties, given by the native Californians, into which the Americans, then beginning to be numerous, would force themselves and shove the native born men aside, monopolizing the dance and the women. This was about $1852^{66}$.

Es necesario considerar quiénes pudieron ser los lectores potenciales del periódico de Hoyle. El pueblo al que pertenece el periódico, Hollister, se funda en 1872. Antes de esa fecha y hasta 1874, los terrenos sobre los que se erige pertenecían al condado de Monterrey. En 1874 se disgregarán y se unirán al

65 The San Francisco Call, July 10 1900: 6e: «TIBURCIO VAZQUEZ.- C. City. Tiburcio Vasquez, el bandido californio, fue colgado en la cárcel del condado, en San José, Condado de Santa Clara el 19 de marzo de 1875, por la muerte de Lander Davidson en Tres Pinos, el 26 de agosto de 1873, mientras Vasquez y su banda estaba robando la tienda de Snyder en esa misma ciudad. En mayo de 1874, Vasquez fue capturado cerca de Los Ángeles por el Sheriff Rowlands, y el 26 d eese mismo mes fue encarcelado en esa ciudad mientras esperaba en ruta hacia Salinas, Condado de Monterrey, lugar desde el que fue llevado con seguridad a San José. Fue condenado el 9 de enero de 1875», Chronicling America: Historic American Newspapers, Library of Congress of the United States, $<$ http://chroniclingamerica.loc.gov/lccn/ sn85066387/1900-07-10/ed-1/seq-6/>.

${ }^{66}$ Truman, 1874: 22: «Mi carrera partió de las circunstancias a las que estaba sometido. Cuando me iba haciendo hombre, tenía la costumbre de asistir a bailes y fiestas que daban los californios nativos, y a esos bailes los americanos, que empezaban a ser numerosos, se autoinvitaban, arrinconando a los hombres nativos y monopolizando el baile y las mujeres. Eso era hacia 1852». 
condado de San Benito. El Censo de 1870 del área de San Benito describe la presencia de ciento sesenta y siete familias. En ellas, 292 individuos se clasifican como varones blancos, 10 como «colored men», en este caso descritos como «Indian», mientras que 235 son mujeres blancas y no hay mujeres descritas en otro grupo. Esto devenga un total de 537 personas. Los nacidos en México, que resulta ser el único área hispanohablante del que hay residentes, así como los nacidos en California con edad suficiente como para haber sido escolarizados en español en la California mexicana, representan menos del quince por ciento del total del $\mathrm{Censo}^{67}$. Aunque en realidad esta no pueda ser considerada como una medida definitiva respecto al número de hablantes de español, o de simpatizantes con la causa california, resulta igualmente muy útil. Tomándola como guía, podemos asumir que en el momento en que se produce su prendimiento, el núcleo de opinión no sería especialmente favorable a un bandido que, a decir de buena parte de la prensa, roba a los que no son californios. La entrevista de Los Angeles Star da una perspectiva más heroica del bandido, mientras que la del Evening Free Lance da una imagen mucho más taimada de él.

Mientras que en la primera de ellas, la angeleña, se plantea como posibilidad el hecho de que Vasquez sea o no un homicida, para el Evening Free Lance no hay duda. En los cincuenta años entre la primera y la segunda, Tiburcio Vasquez ha adquirido un elemento, además, que estaba ausente de la entrevista bilingüe. De pronto, lo vemos convertido en un Don Juan, una perspectiva que ya se intuye en la descripción de Bancroft cuando compara a Murrieta con Vasquez: «Joaquin was of gentle blood, and as handsome, and gay, and chival rous as any youthful knight-errant; Vazquez was a hybrid, half Indian, coarse, treacherous, brutish». Nada encontramos en Bancroft ya de la delicadeza con que se le presenta en Truman, ni de la educación que dirá haber compartido con él Gómez. Antes al contrario, «His boyhood was spent in taming wild mustangs, cutting flesh with bowie-knives, and shooting, dancing the bolero and fandango, and betraying young damsels». Y no solo eso, sino que «Indeed, he was a bedeviled Don Juan at love. Repulsive monster though he was, the dear creatures could not help following him ${ }^{68}$. En la misma línea, uno de los epígrafes de Hoyles reza: «Don Juan proclivities leads to Downfall» ${ }^{69}$, y

${ }^{67}$ Federal Census. Monterey County, 1870.

${ }^{68}$ Bancroft, 1886: 651: «Joaquin era de sangre noble, y guapo, y alegre, y tan caballeroso como cualquier joven caballero errante; Vazquez era un híbrido, medio indio, rudo, traicionero, brutal»; «Pasó su infancia domando caballos salvajes, cortando carne con navajas, y disparando, bailando boleros y fandangos, y burlando a jóvenes damiselas»; «De hecho, era todo un don Juan en el amor. A pesar de ser el repulsivo monstruo que era, las criaturitas no podían dejar de seguirle»; «Sus proclividades donjuanescas lo llevaron a la caída».

${ }^{69}$ Hoyles, 1927: 15. 
explica en él cómo la captura de Vasquez fue posible gracias a la traición de Leiva, un marido ultrajado. Lo que en Bancroft era únicamente un rasgo de carácter se transforma en Hoyle en la causa de su final:

Abadon Leiva [...] was a high caste Chilean who had come to California, bringing with him a beautiful young wife. Even as King David gazed upon the wife of Uriah the Hittite and desired her, so Vasquez looked at the bautiful Senora (sic) Leiva and determined to gain her favors. As David sent Uriah away to war, so Vasquez sent Leiva into the Cantua Canyon to shoe the horses of his followers, and in his absence made merry with the blacksmith's wife ${ }^{70}$.

De esta manera, Vasquez no es solo un bandido que roba y asesina, sino también un individuo concupiscente que va a ser detenido merced a los pecados de su carne, que no a los de su revólver. Tanto Vasquez como Leiva participan ambos, aunque en diferente forma, de la masculinidad degradada de Frazer a la que hemos hecho alusión. En la versión de Bancroft, Leiva es primo del bandido: «Tiburcio's most devoted follower was his cousin, Leiva, and most devotedly he stole Leiva's wife. Yet Leiva remained true to him. What was a wife beside glory and friendship?» ${ }^{71}$ En el momento en que escribe Bancroft se inicia lo que Carey McWilliams denominó «fantasy Spanish heritage», que para cuando escribe Hoyle ya está en todo su esplendor. Los californios ya no tienen voz propia, sino que se han convertido en estampas de un pasado remoto, folclore romantizable:

Dispossessed of their lands and politically disenfranchised, the former rancheros represented no threat to Euro-American supremacy and thus could be safely romanticized. The new popular histories converted Mexican rancheros into "the California Dons," dashing, silver-saddled caballeros who roamed baronial estates from dawn to dusk in a remote Spanish past. The new Dons, however, continued to be inept; incapable of hard work, they lacked the genius or moral strength to develop California's lush, fertile land ${ }^{72}$.

${ }^{70}$ Idem: «Abadon Leiva [...] era un chileno de alta casta que había venido a California, trayendo consigo a su hermosa y joven mujer. De la misma manera que el Rey David había puesto los ojos sobre la esposa de Urian el hitita y la había deseado, igualmente Vasquez miró a la joven Senora (sic) Leiva y se determinó a ganar sus favores. Así como David envió a Uriah muy lejos a la guerra, Vasquez envió a Leiva al Cañón Cantua para herrar los caballos de sus seguidores, y en su ausencia se regocijó con la esposa del herrero».

${ }^{71}$ Bancroft, 1886: 652: «El seguidor más devoto de Tiburcio era su primo, Leiva, y de la misma devota forma le robó a su esposa. A pesar de ello, Leiva siguió siéndole leal. ¿Qué es una esposa frente a la gloria o la amistad?»

${ }^{72}$ Castañeda, 1990: 13: «Desposeídos de sus tierras y alienados políticamente, los antiguos rancheros no planteaban ninguna amenaza a la supremacía euro-americana y, por lo 
Bancroft, en la misma línea en la que más adelante se posicionará la crítica anglosajona -basten como ejemplos Hoyle o Boessenecker- afirma que «[...] neither Joaquin Murieta nor Tiburcio Vazquez were Robin Hoods», aunque continúa, parece que resignado «though with six or eight centuries of historic truth-stretching and romancing they may become such, and, indeed, to many a Pastoral Californian were such in their day» ${ }^{73}$. Poseedor de una fina ironía de la que ya hemos sido testigos, Bancroft justifica el apoyo social de los nativos californios a los bandidos: «Brigandage, when directed against that encroaching and heretical neighbor, the insolent gringo, was a chivalric ideal of the Mexican, and no less so of his Hispano-Californian fellow-citizen $\gg{ }^{74}$.

A partir de la Poética de Aristóteles, María Rosa Álvarez Sellers establece siete elementos que configuran el nudo íntimo de la tragedia clásica, tal y como fue adaptada en el siglo de oro español: catarsis, hamartía, hybris, pathos, mito, mímesis y por ultimo anagnórisis ${ }^{75}$. Berbel lee esos rasgos en las poéticas neoclásicas españolas del XVIII ${ }^{76}$. En la historia que Vasquez presenta de sí mismo nos encontramos con un árbol de tópicos muy semejante lo cual, unido a su condición de lector, nos induce a pensar que es él mismo quien está transformando su biografía en materia literaria.

La historia, tal y como nos la cuenta Vasquez, da inicio en el momento inmediatamente anterior a la catarsis: al enmarcar su muerte dentro del contexto más amplio de su vida, que plantea en tonos trágicos, busca que el horror del ahorcamiento provoque piedad en el lector. A causa de su ignorancia juvenil y movido por su idea del honor, comete involuntariamente un error que le acompañará toda su vida. Según sus palabras, la fuente de su hamartía es el mal trato que reciben los muchachos californios por parte de los estadounidenses recién llegados. Esta situación va a provocar una peripecia, en el sentido clásico y tal y como fue definida por Luzán para el ámbito hispánico: «una

tanto, podían ser romantizados con seguridad. Las nuevas historias populares convirtieron a los rancheros mexicanos en los "Dons de California", galantes caballeros con monturas de plata que regían, desde el amanecer hasta el anochecer, haciendas dignas de barones en un remoto pasado hispánico. Los nuevos Dons, sin embargo, seguían siendo ineptos: incapaces de trabajar duramente, les faltaba el genio o la fuerza moral para desarrollar las fértiles tierras de California».

${ }^{73}$ Bancroft, 1886: 622-623: «Ni Joaquín Murrieta ni Tiburcio Vazquez eran Robin Hoods» «auque con seis y ocho siglos de comprometer la historia y novelarla podrían convertirse en eso, y de hecho así lo fueron para muchos pastorales californios en su tiempo».

${ }_{74}$ Ibidem: 623: «El bandidismo, cuando se dirigía contra el vecino incómodo o herético, el gringo insolente, era un ideal caballeresco tanto para el mexicano como para su conciudadano el hispano-californio».

75 Álvarez Sellers, 1995: 19-47.

${ }^{76}$ Berbel, 2003: 129. 
mudanza de fortuna en contrario de lo que los lances y sucesos de la acción hubiesen prometido hasta ese punto; pero no una mudanza como quiera sino repentina, impensada y contra toda expectación (469-470)». La peripecia de Vasquez, su aventura como bandido, va a estar retroalimentada por el éxito de sus pendencias y, al mismo tiempo, por el orgullo trágico derivado de las mismas, la hybris. No obstante, no deja que su sufrimiento o pathos pase por alto a los lectores, mostrándose preocupado por lo que la prensa dice de él, o lo que sus conciudadanos piensen sobre él. Tras imitar el comportamiento de múltiples otros bandidos -y burladores, en un ejemplo clásico de mimesis-, en último término se produce un doble reconocimiento o anagnórisis: por un lado el bandido es reconocido como tal y por el otro, una vez detenido, reconoce sus crímenes.

Vemos, por tanto, cómo la estructura del personaje literario que Vasquez configura de sí mismo se apoya en las nociones de la tragedia clásica, aurisecular y neoclásica. Esta presentación de los hechos, la justificación de su carrera en una falta contra su honor y la insistencia en la buena crianza que le habían dado sus padres proyecta, o pretende proyectar, a Vasquez como el héroe necesario de y para sus contemporáneos. De esta manera, las fronteras entre la historia y la memoria se diluyen progresivamente ${ }^{77}$ : lo que era memoria en Vasquez se va transformando en historia, toda vez que su yo lírico pasa de ser autobiográfico a vislumbrarse como víctima heroica para unos, y criminal para otros.

De vuelta a la entrevista de Los Angeles Star, el entrevistador le pregunta a Tiburcio Vasquez: «¿Cuál ha sido su carrera de Vd.? ¿Ha sido Vd. ladrón siempre?» Este responde que fue forzado a delinquir por las circunstancias. Se presenta a sí mismo como sujeto a un destino trágico. Conviene notar, asimismo, que el entrevistador se refiere a Vasquez como «ladrón», y no como «asesino», validando así la defensa que el bandido mantenía sobre sí mismo: que sí era un ladrón, pero que nunca había matado a nadie:

No: yo era hombre de bien y trabajador en un tiempo; pero ciertos disgustos y malos tratamientos me obligaron a abrazar la carrera que he llevado. Primeramente

77 En este pasaje, «historia» se refiere a lo que en inglés se designa como Story y no a la History (Geschichte), puesto que este tipo de historia particular, concreta que adquiere forma narrativa y oral (Story) no deja de ser memoria: se refiere a experiencias y testimonios en conjunto, que mantienen una relación recíproca y a veces mimética con aquello que llamamos memoria colectiva y memoria popular. En cambio, la Historia (con mayúscula como le referimos en español a la History, Geschichte) es algo que no se puede separar de la memoria pero que tampoco debe confundirse, al menos académicamente, como señalan estudiosos de la materia como Dominick LaCapra o Francois Hartog, por ejemplo. 
salé para el rancho de los Felix, y luego fui a ver a mi madre, le dije que era necesario que yo saliera a la ventura: mi madre lloró mucho y al último me dio su bendición. Desde entonces he robado todo lo que he podido.

Se me había olvidado decir a Vds. que en 1857 o 1858 fui arrestado en Los Ángeles por robo de algunos caballos que traje de Monterey: me llevaron a San Quentin y después que salí en 1863 he robado diligencias, carros, casas, etc. casi todo el tiempo ${ }^{78}$.

Se aprecia en sus palabras que justifica su conducta ante la imposibilidad de la redención tras la cárcel. De orígenes honrados («mis hermanos son ambos hombres honrados», dice) comienza con hurtos y sus crímenes escalan tras su estancia carcelaria. Cuando más adelante el entrevistador le pregunte sobre la posibilidad de que sea un asesino, la respuesta de Tiburcio Vasquez será vehemente. De hecho, los periódicos de la época recogen que se declaró «not guilty» de los cargos de asesinato (Los Angeles Daily Herald, entre otros). Niega haber tenido ninguna responsabilidad al respecto y afirma que algunos miembros de su cuadrilla habrían decidido cometer el crimen sin su aquiescencia y ni tan siquiera con su conocimiento. Dice:

No he matado a nadie. Yo estoy en un país civilizado y creo que se me juzgará con justicia: si me hallan culpable lo bastante como para merecer la muerte, aquí está mi pescuezo listo. Pero yo no soy sanguinario, solo confieso que he amarrado a algunos y robado a muchos ${ }^{79}$.

Vemos otra de las características que configuran su identidad, y que se pueden leer en paralelo con el corrido de Gregorio Cortés: ejerce violencia contenida, focalizada en aquellos que comenten las injusticias. Además, la opinión de Tiburcio Vasquez sobre la justicia estadounidense, sobre el hecho de su civilidad, resuena con las palabras de Francisco P. Ramírez - «un pueblo tan magnánimo y libre», va a decir- de forma tal que nos induce a pensar si no se tratará de un uso rayano en lo irónico.

Otra de las características es la insistencia en el honor. El entrevistador le fustiga: «Vd. no es franco, nos engaña», a lo que responde: «Lo aseguro como caballero» ${ }^{80}$. Establece una diferencia entre honor y honradez, en el sentido aurisecular hispánico clásico. Tenemos por lo tanto a un bandido que se vio forzado a lanzarse al monte -aunque aún no nos ha explicado por qué en la entrevista del Star- pero que procede de una familia honrada y se considera

\footnotetext{
78 Truman, 1874: 39 .

79 Idem.

80 Ibidem: 40.
} 
honorable. Además marca la diferencia entre robo y asesinato. En la relación de sí mismo en inglés relata una historia semejante a la que según Catherina Watson le había ocurrido con su familia: enterado de que un tratante de ganado se ha enriquecido con una venta, decide hacerle una visita bajo la falsa apariencia de ser esquilador de ovejas. Una vez que consigue acercarse al terrateniente,

He handed me eighty dollars. I told him that that would not do; that I knew all about his affairs; that he had sold nearly $\$ 10,000$ worth of sheep latterly, and that he must have plenty of money buried about the place somewhere. Repetto then protested that he had paid out nearly all the money he had received in the purchase of land; that he had receipts to show for it, etc. I told him that I could read and write and understood accounts; that if he produced his books and receipts, and they balanced accordingly to his statements, I would excuse him. He produced the books, and after examining them carefully, I became convinced that he had told very nearly the truth ${ }^{81}$.

Todas las historias sobre Vasquez insisten en que había estado escolarizado y en que sabía hablar inglés. Sin embargo, esta es la primera ocasión en que encontramos memoria de que él lo diga de sí mismo. Hacia el final de la entrevista en español, dirá que había estado tentado de escribir una carta al periódico para defender su versión de los hechos. Lo veremos a continuación, pero antes sus explicaciones de caballero honrado:

I then expressed my regrets for the trouble I had put him to, and offered to compromise. I told him I was in need of money, and that if he would accommodate me with a small sum I would repay him in thirty days with interest at $1 \frac{1}{2} 2$ per cent per month. He kindly consented to do so $^{82}$.

Además de la supuesta caballerosidad con la que se presenta, un elemento más lo deja caber dentro de la definición de bandido social: su respuesta acerca de la opinión pública y la recepción que le ha dado el pueblo. A la pregunta

${ }^{81}$ Ibidem: 19: «Me dio ochenta dólares. Le dije que no serviría de nada, que lo sabía todo sobre sus asuntos; que había vendido últimamente ovejas por valor de casi $\$ 10.000$, y que seguro que tenía mucho dinero enterrado por allí cerca. Repetto protestó y dijo que había usado casi todo el dinero que había ganado para pagar la tierra; que tenía recibos, ect. Le dije que yo sabía leer y escribir y que entendía las cuentas; que si me enseñaba sus libros y recibos y los balances estaban acordes con lo que me acababa de decir, que le excusaría. Me mostró los libros y, después de examinarlos cuidadosamente, me convencí de que me había dicho casi la verdad».

${ }^{82}$ Idem. 
«¿Está usted satisfecho del trato que le dan aquí?» Responde: «Demasiado. Nunca creí que la gente a quien he dado tanto susto me iba a tratar $\tan$ bien ${ }^{83}$.

Un último detalle, que nos aporta un elemento más para comprender al personaje: es autoconsciente de su fama como bandido. Esto es, él mismo participa como espectador de la creación de su mito. Y no solo eso, sino que afirma haber tenido la voluntad de colaborar directamente, como una voz más, en esa creación. El entrevistador le pregunta por un periódico en español en el que el propio entrevistador escribe y del que parece que Vázquez era lector. Dice Tiburcio Vasquez:

Yo he guardado todo lo que ustedes decían de mí, Hace algunos días tenía intenciones de escribirles una cosa para que la publicaran, enviando dinero al mismo tiempo, porque yo creo que Uds. no tendrían ningún reparo en poner mi escrito aun cuando fuera de un ladrón: pero ya estoy preso y es tarde: siento no haber tenido ocasión de mandarles mi carta ${ }^{84}$.

\section{CONCLUSIONES}

En vista de lo anterior, la figura de Tiburcio Vasquez se erige como símbolo de la identidad california, al tiempo que supone un eslabón más en la construcción folclórica del pasado californio. Su carrera como forajido resuena con la de Murrieta pero, al mismo tiempo, hace eco también al constructo del pasado mítico californio de caballeros elegantes de dudosa sombra y señoritas a caballo tal y como la ha reflejado Charles Christian Nahl en su obra pictórica The Fandango (1873).

La brecha entre los californios y los no californios, entre los hablantes de español -incluso los bilingües- y los hablantes de inglés se hace cada vez más grande en California. Mediada la década de los setenta, en las postrimerías de la vida de los que habían conocido como adultos la California mexicana, la aparición de un bandido californio que respeta a sus coterráneos y ataca a los estadounidenses, se erige en símbolo de la sociedad que desaparece a los ojos del gran público. De hecho, Vasquez es al mismo tiempo el último estertor de esa sociedad que desaparece y, por mor de la reescritura de la historia, se convierte también en el héroe necesario de la folclorización del pasado mexicano y californio. Murrieta, Vasquez y tantos otros individuos surgidos en los espacios en sombra entre Estados Unidos y

\footnotetext{
83 Ibidem: 43 .

84 Ibidem: 44.
} 
México en la segunda mitad del XIX cierran la puerta al pasado mexicano y comienzan la interpretación de un nuevo futuro estadounidense para los territorios de lo que había sido la frontera norte de México. Son frontera en sí mismos, al tiempo que defienden los privilegios de los que disponían con la línea de la frontera que se había desplazado tras la firma del Tratado de Guadalupe-Hidalgo.

\section{BiBLIOGRAFÍA}

Álvarez, Salvador, "Conquista y encomienda en la Nueva Galicia durante la primera mitad del siglo XVI: bárbaros y civilizados en las fronteras americanas", Relaciones, 116/XXIX (México, 2008): 135-188.

Álvarez Sellers, María Rosa, La tragedia española en el siglo de Oro, Vitoria, Diputación Foral, 1995.

Andrews, Hazel y Roberts, Les (eds.), Liminal Landscapes. Travel, Experience and Spaces in-between, London, Routledge, 2012.

Bancroft, H. H., California Pastoral, San Francisco, The Bancroft Press, 1886.

Banner, Stuart, "Preparing to Be Colonized: Land Tenure and Legal Strategy in Nineteenth-Century Hawaii", Law and Society Review, 39/2 (Hoboken, Nueva Jersey, 2005): 273-314.

Berbel Rodríguez, José J., Orígenes de la tragedia neoclásica española, Sevilla, Universidad, 2003.

Boessenecker, John, "California Bandits: Social Bandits or Sociopaths?", Southern California Quarterly, 80/4 (California, 1998): 419-434.

Bolton, Herbert E., "The Mission as a Frontier Institution in the Spanish-American Colonies", The American Historical Review XIII/1 (Bloomington, 1997): 42-61.

Castañeda, Antonia I., "Gender, Race, and Culture: Spanish-Mexican Women in the Historiography of Frontier California", Frontiers: A Journal of Women Studies, 11/1 (Ohio, 1990): 8-20.

Castillo, Pedro y Camarillo, Albert, Furia y muerte: los bandidos chicanos, Berkeley, University of California Press, 1973.

Cohen, Anthony P., "Personal Nationalism: a Scottish View of Some Rites, Rights and Wrongs", American Ethnologist, 23/4 (Hoboken, Nueva Jersey, 1996): 802-815.

Davobe, Juan P., Nightmares of the Lettered City: Banditry and Literature in Latin America, 1816-1929. Illuminations, Cultural Formations of the Americas, Pittsburgh, University of Pittsburgh Press, 2007. 
Delanty, Gerar, Community, Barcelona, Graó, 2003.

Desty, Robert (ed.), Constitution of the State of California adopted in 1879, San Francisco, Bancroft-Whitney Company, 1893.

Echavarría, José María, Circular del Presidente Interino de los Estados Unidos Mexicanos acerca de la capitalidad de Los Ángeles sobre la Alta California, México, 23 de mayo de 1835.

Gates, Paul, "The California Land Act of 1851", California Historical Quarterly, 50/4 (California, 1971): 395-430.

Gennep, Arnold van, Los ritos de paso, Madrid, Alianza, 2008 [1909].

Giddens, Anthony, The Nation-State and Violence, vol. II, California, UC Press, 1985.

Giddens, Anthony, The Consequences of Modernity, Stanford, Stanford University Press, 1990.

Guerra, Francois-Xavier, Modernidad e independencias. Ensayos sobre las revoluciones hispánicas, Barcelona, Mapfre, 1992.

Hittel, Theodore H. (comp.), "Constitution of the State of California... 1849..... The General Laws of the State of California from 1850 to 1864, inclusive, San Francisco, A. L. Bancroft and Company, 1872, vol. I: 83-242.

Hobsbawn, Eric J., Bandidos, Barcelona, Crítica, 2001.

Hoyle, Millard, Crimes and Career of Tiburcio Vasquez, The Bandit of San Benito County and Notorious Early California Outlaw, Hollister, San Benito County Historical Society, 1927. También editado en el Evening Free Lance de Hollister.

Kanellos, Nicolas, y Martell, Helvetia, Hispanic Periodicals in the US. Origins to 1960, Houston, University of Texas, 1960.

Lamar, Howard R., "Land Policy in the Spanish Southwest, 1846-1891: A Study in Contrasts", The Journal of Economic History, 22/4 (Cambridge, 1962): 498-515.

Lamar Prieto, Covadonga, "El discurso de Pío Pico y los primeros tiempos del español en la California estadounidense", Belén Villarreal (ed.), Transnationality in the Luso Hispanic World, California, UCPress, 2012: 93-107.

Lamar Prieto, Covadonga, "Land Ownership as a Resource for Constructing Otherness in California", Teresa Fernández Ulloa (ed.), Otherness in Hispanic Culture, Cambridge Scholars Publishing, 2013: 387-409.

Lamar Prieto, Covadonga, "From Native Language to Foreign Language: Spanish in the XIX Schools", Voices, 1 (2014): 7-13. 
Layne, J. Gregg, "Annals of Los Angeles part I, From the Founding of the Pueblo to the American Occupation", California Historical Society Quarterly, 13/3 (California, 1934): 195-234.

Limbaugh, Ronald H. "Making Old Tools Work Better: Pragmatic Adaptation and Innovation in Gold-RushTechnology", California History, 77/4 (California, Winter 1998/1999): 24-51.

Mason, William Marvin, The Census of 1790. A Demographic History of Colonial California, Banning, California, Ballena Press Publications, 1998.

Montejano, David, Anglos and Mexicans in the Making of Texas, 1836-1986, Austin, UT Press, 2003.

Moreno de Alba, José Guadalupe y Perissinotto, Giorgio, "Algunas consideraciones sobre el español de Santa Bárbara", Nueva Revista de Filología Hispánica, XXXVI/1 (México, 1998): 171-191.

O’Sullivan, John L., “Annexation”, The United States Democratic Review, 17/85 (Nueva York, julio-agosto 1845): 5-10.

Padilla, Genaro, My History, not Yours: the Formation of Mexican American Autobiography, Wisconsin, University of Wisconsin Press, 1993.

Parodi, Claudia, "El otro México: español chicano, koineización y diglosia en Los Ángeles, California", R. B. Villanueva and P. M. Butragueño, Realismo en el análisis de corpus orales: Primer Coloquio de Cambio y Variación Lingüística, México D.F., El Colegio de México, 2011: 217-243.

Parra, Max, "Pueblo, bandidos y Estado en el siglo XIX mexicano. Notas a partir de El Zarco de Ignacio Manuel Altamirano", The Colorado Review of Hispanic Studies, 4 (Boulder, Colorado, 2006): 65-76.

Parra, Max, "Pancho Villa y el corrido de la Revolución", Caravelle. Cahiers du monde hispanique et luso-bresilien (CMLHB), 88 (Toulouse, septiembre 2007): 139-149.

Revere, Joseph Warren, A Tour of Duty in California, Nueva York, Joseph N. Baestier, 1846.

Robinson, W. W., Land in California. The Story of Mission Lands, Ranchos, Squatters, Mining Claims, Railroad Grants, Land Scrip, Homestead, Berkeley y Los Angeles, University of California Press, 1948.

Ruiz de Gordejuela Navarro, Jesús, "La independencia de México y las misiones de las Californias: españoles versus mexicanos, 1821-1833”, Boletín Americanista, 57 (Barcelona, 2007): 219-232.

Sánchez Albornoz, Julio, Despoblación y repoblación del Valle del Duero, Buenos Aires, Instituto para la Historia de España, 1996.

Servín, Miguel, "The Secularization of the California Missions: A Reappraisal", Southern California Quarterly, 47/2 (California, 1965): 133-149. 
Turner, Victor W., The Ritual Process: Structure and Anti-Structure, Chicago, Aldine Pub. Co., 1969.

Truman, Ben C., Life, Adventures and Capture of Tiburcio Vasquez. The Great California Bandit and Murderer, Los Angeles, Los Angeles Daily Star, 1874.

US Statuses at Large, Treaty of Peace, Friendship, Limits, and Settlement with the Republic of Mexico, 1848, vol. XI: 922-943.

US Statuses at Large, Act to Ascertain and Settle the Private Land Claims in the State of California, vol. IX. 31 ${ }^{\text {st }}$, Congress session II, 1951, ch. 41: 631-635.

Zamorano, Agustín V. y Figueroa, José, Proclama del 14 de febrero como día festivo en honor de Vicente Guerrero, 1834.

Zentella, Ana Celia, Growing up Bilingual: Puerto Rican Children in New York, Oxford, Blackwell Publishers, 1997.

Fecha de recepción: 21 de febrero de 2014.

Fecha de envío de las modificaciones: 28 de julio de 2014.

Fecha de aceptación: 1 septiembre de 2014.

\section{Bandits and Californio identity in the second half of the nineteenth century: Tiburcio Vasquez}

The bandit Tiburcio Vasquez developed his career at a time of political and social struggle for California and the Californios, given that they became part of the United States of America after 1848. This paper examines the bilingual interview that Vasquez gave the day before his death sentence, together with other documentary sources about him in English and Spanish. I use the conceptual frame of liminality in order to expose the tools used to folklorize the past of the Californios. I examine conceptualizations about Vasquez, and who defined them, and the conclude that the Californio bandits, and especially Vasquez, represent the partial dissolution of the Californio identity, under pressure from the new social and political framework imposed by the United States.

Key words: Bandit; California; nineteenth century; liminality; bilingualism; Californio. 